\title{
THE HALOTHANE-ETHER AZEOTROPE: AN ILLOGICAL MIXTURE
}

\author{
Michael Johnstone, M.D., F.F.A.R.C.S., ${ }^{*}$ Vincent Evans, M.B., D.A., \\ PÁTRICK V. MURPHY, M.B., B.CH., B.A.O. $\dagger$
}

THE HALOTHANE-ETHER AZEOTROPE was introduced into clinical anaesthesia by Hudon, Jacques, and Boivin ${ }^{1}$ in an attempt to counteract the cardiovascular and respiratory effects of halothane. Responsibility for its inception was also claimed by Lott ${ }^{2}$ who described it as non-inflammable and suggested that the addition of ether to halothane might diminish what he called the toxicity of the latter drug which, for reasons unspecified, reminded him of chloroform.

The optimal proportions suggested for the azeotrope were 68.3 parts of halothane to 31.7 parts of ether. ${ }^{3}$ It was recognized that, although the mixture of the liquids was azeotropic in all proportions, the suggested $2: 1$ ratio (approximately) was safest from the point of view of fire and explosion hazard. It appears to have been assumed that the dose range of the mixture should be similar to that of halothane, that is, 1 per cent to 4 per cent of the vapour $\mathrm{v} / \mathrm{v}$ in the inspired gases, and this range of concentrations was shown to be noninflammable in air or oxygen, the lower limit of inflammability being 10.9 per cent $\mathrm{v} / \mathrm{v}$ in oxygen. ${ }^{1}$ Raventos and Dee ${ }^{4}$ stated the lower limit of inflammability to be as low as 5.2 per cent $\mathrm{v} / \mathrm{v}$ in oxygen-nitrous oxide mixtures.

No reference has been made to the inflammability of the liquid in oxygen atmospheres similar to those encountered in the vaporizing chambers of the commonly used anaesthetic machines. As most of these vaporisers utilize the principle of saturating a fraction of the input gases with the vapour and subsequently diluting the mixture with by-passed gases, the lower limits of inflammability in oxygen, either as defined by Boivin ${ }^{3}$ or by Raventos, ${ }^{4}$ must be well below the concentration emerging from the vaporizing chambers; one must therefore assume that the risk of fire and explosion from electrostatic and other sources has not been eliminated.

There is no doubt that the liquid azeotrope in the prescribed proportions is non-flammable in air. Nevertheless, it is highly inflammable in oxygen and has already been responsible, in the experience of one of us (M.J.), for one minor conflagration which was extinguished with difficulty. If the fire hazard is to be avoided completely it will be necessary to use only air to vaporize the liquid, and this requires the use of non-return breathing equipment with assisted respiration. This method, besides being extravagant and perhaps wasteful, causes atmospheric contamination which theatre personnel often find objectionable. A modification of this method, combining low concentrations of the azeotrope in air with supplementation by intravenous agents, has been

*Department of Anaesthetics, Royal Infirmary, Manchester, England.

†Present address: Crumpsall Hospital, Manchester, England. 
described, ${ }^{5}$ and indicates that effective anaesthesia is no longer dependent on a constant supply of compressed gases; this system of anaesthetic management will be invaluable in circumstances where compressed oxygen is unavailable. There is no reason to doubt that halothane, administered in a somewhat similar but more convenient manner, should be equally, if not more, effective. ${ }^{*}$

Pharmacological investigations of the azeotrope were not reported before the appearance of the first clinical report. ${ }^{1}$ It appears to have been assumed empirically that the accepted sympathomimetic action of ether should successfully antagonize the cardiovascular effects of halothane and thereby raise its margin of safety. It does not appear to have been considered that the effects of halothane on sympathetic activity may expose the true action of ether on the myocardium.

The successful use of the azeotrope in over 2,000 cases was described in this report, using various methods of administration which included the Boyle, Fluotec, and Heidbrink vaporizers in semi-closed and closed circuits with, oxygen; the open mask drop was also used with continuous administration of oxygen by nasopharyngeal catheter. Respiratory depression and apnoea occurred with the closed and semiclosed methods and hypotension was encountered but was an inconstant finding.

Dobkin, Drummond, and Purkin ${ }^{7}$ investigated the effects of the azeotrope on the circulatory dynamics and other functions of 50 patients. The method of anaesthesia consisted of pethidine-atropine premedication, induction with thiopentone-gallamine, and maintenance with nitrous oxide, oxygen, azeotrope 0.5 per cent to 1.0 per cent $\mathrm{v} / \mathrm{v}$ with additional gallamine for relaxation; artificial ventilation was provided with an automatic ventilator and a nonrebreathing system was incorporated. They concluded that circulatory dynamics did not present the same problems as they had encountered with halothane, although some of their dogs anaesthetized with the mixture developed serious and sometimes fatal cardiac arrhythmias when adrenaline was injected intravenously.

In a second and more elaborate experimental study in dogs, Dobkin, Harland, and Fedoruk ${ }^{8}$ compared the cardiovascular and respiratory effects of 2 per cent $\mathrm{v} / \mathrm{v}$ halothane in oxygen with the azeotrope 3 per cent $\mathrm{v} / \mathrm{v}$ in oxygen. They observed that the differences, though small, were statistically significant and concluded that they found the azeotrope easier to use than halothane. Their use of three references to substantiate the questioning of the report that halothane prevents surgical shock is misleading: two of the references are unrelated to shock and the third noted that although profound hypotension was observed during halothane, shock did not appear. If the suggestion that halothane prevents the appearance of shock and facilitates the resuscitation of shocked patients proves to be correct, there is no doubt that the drug can be regarded as having "distinctly individual features." 9

Dechene and Hebert ${ }^{10}$ reported the successful use of the azeotrope in a large number of pulmonary operations, using the azeotrope in low concentrations combined with nitrous oxide, oxygen, and suxamethonium. Wyant, Merriman, Harland, and Donaldson, ${ }^{11}$ using higher doses of the mixture in a closed circuit 
with oxygen, observed systolic pressures in volunteers as low as $42 \mathrm{~mm}$. $\mathrm{Hg}$ with the cardiac output too low to be measured. The observations of the latter workers do not indicate that either prevents the cardiovascular and respiratory effects of halothane and it may, in fact, be adversely additive, as suggested by Raventos and Dee. ${ }^{4}$

Shortly after the appearance of the initial clinical report on the azeotrope we decided to compare its effects with those of halothane in a series of patients undergoing prolonged operations requiring general anaesthesia. Adult neurosurgical cases offered the best opportunities because our premedication was standardized to pethidine $50 \mathrm{mg}$. with atropine $0.6 \mathrm{mg}$., and induction and intubation were performed with thiopentone-suxamethonium. The proposed plan was to maintain anaesthesia with $10 \mathrm{~L}$. per min. of a 50 per cent mixture of nitrous oxide and oxygen through a Fluotec vaporizer set at 2 per cent halothane. After approximately an hour on this mixture, the Fluotec was to be turned off and the gas mixture directed through an Azeotec; specially constructed for the purpose, set at 2 per cent. Non-rebreathing apparatus (Ruben valve) was to be used and the respiratory minute volume constantly measured with a Wright respirometer, respiration being assisted if the minute volume dropped below $6 \mathrm{~L}$. per min. Systolic blood pressures were to be measured by sphygomanometry every few minutes and the pulse rate charted in the usual manner. The investigation came to an alrupt hale after the completion of the first case, details of which are as follows.

A thin female of 34 years of age had signs and symptoms of a tumour in the posterior cranial fossa, but was conscious, rational, and well nourished, with normal heart and lungs. Her blood pressure was $110 / 70 \cdot$ Premedication was pethidine $50 \mathrm{mg}$. and atropine $0.6 \mathrm{mg}$; induction, thiopentone $200 \mathrm{mg}$. with suxamethonium $50 \mathrm{mg}$; and maintenance, halothane 2 per cent with $10 \mathrm{~L}$. per min. nitrous oxide and oxygen 50 . per cent. Intravenous gluco-saline drip at 30 drops per mih. was given and the operation was performed with the patient in the sitting position.

During the first hour of halothane-nitrous oxide anaesthesia the blood pressure remained steady'at $75 \mathrm{~mm}$. Hg systolic with adequate brain pulsation. The halothane was then stopped and the azeotrope 2 per cent introduced. A slowly progressive decline in blood pressure then commenced, without change in pulse rate, and after $20 \mathrm{~min}$. reached the alarmingly low level of $30 \mathrm{~mm}$. $\mathrm{Hg}$ systolic, the radial pulse being barely perceptible. Brain pulsation was no longer visible and a patchy cyanotic pallor appeared on the peripheral parts of the body, especially the fingers, hands, and forearms. Throughout the period of circulatory collapse respiration was deep and regular, of the hypoxic type, and the radial pulse was regular and very feeble at 90 beats per min.; neither assisted nor controlled respiration was required at any time. The azeotrope and nitrous oxide were immediately withdrawn and oxygen only administered for the next $3 \mathrm{~min}$. during which time the normal pink colour of the skin gradually returned and pulsations became visible in the brain. Halothane 2 per cent in oxygen- was then added and the blood pressure gradually returned during the next few minutes to $70 \mathrm{~mm}$. $\mathrm{Hg}$ systolic. The halothane 2 per cent 
in oxygen was continued for the next 2 hours and the operation successfully completed, the systolic pressure remaining about $75 \mathrm{~mm}$. $\mathrm{Hg}$. Consciousness returned approximately one hour postoperatively and, apart from some restlessness and confusion for the next twenty-four hours, recovery was uneventful.

For the next twelve months our interests were directed towards the development of a technique whereby surgical anaesthesia could be rapidly induced and maintained with halothane-a ygen only, all other agents, including preoperative sedatives, atropine, thiopentone, nitrous oxide, pethidine, relaxants, and vasopressors being eliminated. Early in the investigation it became obvious that deep surgical anaesthesia could not be induced expeditiously in all cases with 3 per cent halothane in the respiratory minute volume of oxygen. After careful trials we discovered that concentrations from 6-10 per cent of halothane in $5 \mathrm{~L}$. of oxygen could be safely used for the induction of surgical anaesthesia of sufficient depth to permit easy intubation after 2-4 miry.; thereafter any required depth of anaesthesia could be provided with smaller amounts of halothane. A specially adapted Fluotec was provided for this purpose and atropine was to a large extent eliminated because it was realized that it of ten caused uhdesirable distortion of the cardiovascular picture of halothane anaesthesia. Full details of this work are awaiting publication.

While the halothane-oxygen anaesthesia was being developed, we applied the procedure known as vasculometry and vasculography to help in assessing. the effect of various drugs on the cardiovascular system. The apparatus consists of a small carbon microphone, energized by a $1.1 / 2$ volt dry battery, placed over the radial pulse or on the pulp end of a digit, and observing the pulsations on a small voltmeter, as described by Keating. ${ }^{12}$ If the leads in to the voltmeter are tapped in parallel and fed into an electrocardiograph, a pulse tracing is obtained on which change in amplitude, form, rate, and rhythm are clearly recorded: the latter adaptation has been reported by Lax,' Feinberg, and Cohen ${ }^{13}$ and called a vasculograph. A somewhat similar principle of monitoring the circulation has been applied by Schotz. Bloom, Helmsworth, Dodge, and Birkmire $^{14}$ who claim that the vasculogram is a reliable index of changes in the cardiac stroke volume output. It is beyond the scope of the present report. to enter into a detailed discussion of the significance of vasculography in clinical practice, but we have accepted the precept that an increase-in the amplitude of the peripheral pulse wave indicates either vasodilation or an increase in the cardiac output, according to the behaviour of the blood pressure. Similarly a decrease in the amplitude of the pulse wave means either vasoconstriction or a diminished cardiac output, again according to the hehaviour of the blood pressure. ${ }^{15,16,17}$ After considerable experience in the clinical use of vasculometry we agree with Schotz et al. ${ }^{14}$ and $\mathrm{Lax}^{13}$ that it, in conjunction with vasculography and sphygomanometry, represents a practical, convenient, and reliable means of monitoring the behaviour of the eirculatory system in the anaesthetized patient.

Having achieved the aim of using halothane-oxygen only for all clinical investigations concerning halothane and at the same time having acquired 
a reliable means for constantly recording the state of the circulation, particularly at very low pressures, we decided to look again at the azeotrope which was still attracting attention., We felt that the cardiovascular collapse encountered in our one case may have been coincidental to the use of the azeotrope and may perhaps have been more closely related to posture or to the nature of the operation.

\section{METHOD}

Elderly patients with normal cardiovascular and respiratory systems were selected. For the first few cases only those for cysto-diathermy were chosen as this procedure was usually sufficiently prolonged to permit a thorough investigation and seldom provokes the reflex circulatory effects of trauma. Subsequently, more major surgical operations were included and a total of twenty patients was investigated.

Premedication. Ten of the patients received no preoperative drugs of any kind. Each of the others received pethidine $50 \mathrm{mg}$. and promethazine $50 \mathrm{mg}$. itwo hours preoperatively.

Induction. Anaesthesia was induced in each patient with halothane 10 per cent in oxygen $5 \mathrm{~L}$. per min. from a Fluotec (type $\mathrm{mj}$ ) into a Waters' bag without the soda lime canister. There was spontaneous respiration. Anaesthesia of a depth sufficient to permit the insertion of a cuffed endotracheal tube was achieved in from $2-4 \mathrm{~min}$.

Maintenance. After the insertion of the endotracheal tube halothane, 2-3 per cent in $10 \mathrm{~L}$. per min. of oxygen into a Waters' bag with a non-return valve (Ruben) and a Wright respirometer incorporated was given. After $30 \mathrm{~min}$., the Fluotec was turned off and the oxygen passed through an Azeotec set at 3 per cent, in accordance with Dobkin's experimental plan. ${ }^{8}$

Ventilation. Respiration was assisted gently by hand if the respiratory minute volume dropped below $10 \mathrm{~L}$. per min. The precise effects of the azeotrope on respiratory activity were not measured. From the published reports it is obvious that it causes respiratory depression when administered in effective doses and it is impossible with any anaesthetic agent to achieve adequate surgical relaxation without causing some degree of depression. Although respiratory depression has little effect on oxygen uptake during halothane anaesthesia, ${ }^{18}$ it limits the uptake of anaesthetic agent and output of $\mathrm{CO}_{2}$, thereby introducing a variable which will affect the-cardiovascular reactions: it was mainly to eliminate this variable that assisted respiration was used. Because of its extravagance this method is not recommended for routine clinical use, closed systems being preferable.

Monitoring. The systolic blood pressure (digital) was recorded at frequent intervals with a sphygmomanometer and vasculometer. Vasculograms were recorded before induction, immediately after the insertion of the endotracheal tube, after $30 \mathrm{~min}$. of halothane anaesthesia, at frequent intervals during the administration of the azeotrope, and at: 3-5 min. intervals after the withdrawal of the azeotrope and the re-introduction of halothane. 


\section{RESULTS}

From the surgical point of view there were no obvious differences between halothane and azeotrope anaesthesia. Muscular relaxation was adequate in all cases, which included a few lower abdominal laparotomies, and spontaneous respiration persisted with quiet and easy diaphragmatic respiration. Respiratory depression was moderate, transient, and easily controllable. The lungs remained easily inflatable and free from secretions. Bleeding from cut surfaces was minimal and sweating did not occur. The pupils remained constricted in all patients. The recovery of consciousness was always prompt and free from restlessness, delirium, and vomiting.

The cardiovarscular reactions to the azeotrope, when administered in the above manner, were unlike those provoked by halothane and the pattern of change was remarkably constant. Halothane caused the usual hypotension coincident with vasodilatation, the hypotension being maximal during inductions and settling at a higher level when surgical anaesthesia was established and the operation started. The pulse rate usually decreased slightly but remained within normal limits in all cases. The hypotension was invariably associated with a considerable increase, often five-fold, in the amplitude of the pulse wave with a deepening of the incisura and an increase in the amplitude of the dicrotic wave in those patients in whom the dicrotic wave was present before induction. The blood pressure and the amplitude of the pulse wave were unaffected by intermittent positive pressure inflation of the lungs and the duration of anaesthesia had little effect on them.

A further decline in the blood pressure followed the change to the azeotrope in twelve patients. The decline had usually started after $5 \mathrm{~min}$. inhalation of the mixture and was slowly progressive during the experiment, the lowest level reached being $45 \mathrm{~mm}$. $\mathrm{Hg}$ systolic after $25 \mathrm{~min}$. of azeotrope anaesthesia. The rate of fall was accentuated by intermittent positive pressure inflation of the lungs, using pressures well within the normal range. In the remaining patients, the blood pressures were unaltered by the azeotrope. The azeotrope hypotension was associated with a patchy cyanotic pallor of dependent parts in six pitients, clear evidence of circulatory stasis.

In all patients, including those with unaltered blood pressures, the azeotrope caused a progressive decrease in the amplitude of the pulse wave, an effect which was intensified by intermittent positive pressure inflation of the lungs. Blood pressure and pulse wave returned to their pre-azeotrope levels within a few minutes after the resumption of 2 per cent halothane anaesthesia.

After the complete elimination of the azeotrope a higher dose of halothane -6 per cent in oxygen $5 \mathrm{~L}$. per min. with assisted respiration-was given to three patients to reproduce a hypotension of similar degree to that encountered during the administration of the azeotrope, in each case $50 \mathrm{~mm} . \mathrm{Hg}$ systolic. In each instance the pulse wave during halothane hypotension was considerably higher than the wave associated with the azeotrope; the typical sequence of change in the pulse wave and blood pressure is illustrated in Figure 1. 


\begin{tabular}{|c|c|c|c|}
\hline $\begin{array}{l}\text { ANAESTHETIC } \\
\text { AGENT }\end{array}$ & $\begin{array}{l}\text { TIME } \\
\text { (mins) }\end{array}$ & $\begin{array}{l}\text { PULSE WAVE } \\
\text { recorder sensitivity } \mathrm{Im} / \mathrm{lcm} \text {. }\end{array}$ & $\begin{array}{l}\text { SYSTOLIC } \\
\text { PRESSURE } \mathrm{mm} \mathrm{Hg} .\end{array}$ \\
\hline $\begin{array}{l}\text { Before } \\
\text { induction }\end{array}$ & $\begin{array}{c}0 \\
2 i\end{array}$ & & 130 \\
\hline $\begin{array}{c}\text { FLUOTHANE } \\
10 \%\end{array}$ & 4 & & 70 \\
\hline $\begin{array}{c}\text { PLUOTHANE } \\
2 \%\end{array}$ & 30 & $11^{-\cdots}$ & 78 \\
\hline $\begin{array}{c}\text { AZEOTROPE } \\
3 \% \\
\end{array}$ & 37 & & 50 \\
\hline $\begin{array}{c}\text { FLUOTHAME } \\
2 \%\end{array}$ & 44 & & 70 \\
\hline $\begin{array}{c}\text { PLUOTHANE } \\
6 \%\end{array}$ & 49 & & 50 \\
\hline $\begin{array}{c}\text { FLUOTHANE } \\
1 \%\end{array}$ & 63 & & 85 \\
\hline
\end{tabular}

FIgURE 1. Vasculography during anaesthesia in a male of 63 years undergoing suprapubic prostatectomy. Heart and lungs are normal; blood pressure 130/90. No premedication was given. Anaesthesia was induced and maintained with halothaneoxygen; azeotrope was added after thirty minutes. Note the considerable fall in the amplitude of the pulse wave and in the systolic pressure. The induction of a similar degree of hypotension, $50 \mathrm{~mm}$. $\mathrm{Hg}$ systolic, with a high dose of halothane at 49 minutes was not associated with a significant decrease in the amplitude of the pulse wave. The final tracing was obtained as the operation was finishing.

\section{Discusston}

The empirical assumption that ether may antagonize the circulatory effects of halothane may be correct when low and ineffective doses of the drugs are used. In these circumstances, the dose of halothane is too small to have any significant influence on autonomic activity and the even-lower dose of ether will probably not impair circulatory dynamics, although, when clinically effective doses of the azeotrope are administered, it is evident that the ether 
fraction rapidly induces signs of acute circulatory failure in a large proportion of patients already satisfactorily anaesthetized with halothane.

To obtain this reaction to ether it may seem that we have used unnecessarily large doses of halothane, the administration of halothane 10 per cent in oxygen being contrary to previous recommendations. ${ }^{19}$ In developing this apparently high-dose technique we were interested primarily in finding a practical and safe procedure for the induction and maintenance of anaesthesia, applicable in all clinical circumstances and independent of clumsy equipment; we were also interested in defining the capabilities of halothane when used as a sole agent for all types of surgical operations. In the course of our investigations it became obvious that it was difficult to induce a reasonable depth of surgical anaesthesia with halothane 2 per cent in oxygen, although this dose was effective, when combined with nitrous oxide: several of the more robust patients were still objecting after inhaling 2 per cent halothane in oxygen for 20 minutes. The dose was gradually increased and eventually the $6-10$ per cent range was adopted for the induction of anaesthesia. Satisfactory results have now been obtained in many hundreds of patients and the procedure has been subjected to special investigations relating to cardiovascular and respiratory reactions, details of which will: be published elsewhere.

Many patients, on recovering consciousness after the induction of anaesthesia with halothane 10 per cent in oxygen, have no unpleasant recollections and several were unable to recall any smell or other subjective experience. Attempts to achieve this type of induction with the azeotrope 10 per cent in oxygen had to be abandoned as several patients objected violently to the intolerable pungency of the ether fraction. The addition of ether to halothane for the purpose of inducing anaesthesia can therefore be regarded as highly objectionable and possibly dangerous because of the explosion hazard when effective concentrations of the mixture are mixed with oxygen. It was therefore impossible to conduct a truly comparative study of halothane and its ether azeotrope. It is not improbable, however, that the halothane-azeotrope sequence which we adopted for our investigation produced cardiovascular reactions similar to those induced ${ }_{\$}$ by the azeotrope used alone: the circulatory collapses observed by us appear very similar to those described by Wyant et $a l,{ }^{11}$ using the azeotrope in a closed circuit.

It would appear that the introduction of the azeotrope into clinical practice was at least premature. The cause and significance of the cardiovascular reaction to halothane are not yet fully appreciated and it would be most unwise to assume that they are detrimental to the patient. Any attempt to influence them, particularly by the use of agents known to be myocardial depressants, may do more harm than good. We now have reliable evidence indicating that halothane causes depression of sympathetic actipity and its haemodynamic actions can be correlated, at least in part, to its effects on autonomic nervous activity. ${ }^{9}, 20,21,22$ It is fully recognized that the administration of surgically ineffective doses of ether in the presence of sympathetic blockade at any level causes a rapidly progressive circulatory failure, survival from its toxic effect being dependent on an intact sympathetic nervous system. ${ }^{23}$ 
The sequence of events which we have observed following the administration of ether to patients anaesthetized with halothane has a striking similarity to that described by Brewster, Isaacs, and Andersen ${ }^{23}$ in dogs following the inhalation of ether after sympathetic blocks had been induced at various levels. It can therefore be concluded that there are neither physical nor pharmacological grounds to justify the administration of mixtures of ether and halothane to patients. Intensive clinical experience in, many parts of the world has indicated that halothane by itself is perfectly capable of providing safe, efficient, and easily reversible anaesthesia without sequelae of any kind when administered in a competent manner. It is not improbable, however, that its unique pharmacological properties may profoundly alter the pharmacological actions of other drugs.

\section{SUMMARYY}

1. The halothane-ether azeotrope 3 per cent in oxygen has been administered to twenty patients already adequately anaesthetized with halothane. Respiration was artificially maintained between 8-10 L. per min., using non-return breathing equipment.

2. Systolic blood pressures were frequently recorded by sphygmomanometry and vasculometry. The amplitude of the peripheral pulse was continuously displayed by a simple vasculometer and vasculograms =were obtained at frequent intervals.

3. It was observed that the azeotrope in most patients caused a progressive decline in blood pressure which reached profound levels in five patients. The hypotension was associated with a decrease in the amplitude of the pulse wave in all cases and circulatory stasis with cyanosis was seen in six cases.

4. It is concluded that the administration of mixtures of ether and halothane is illogical and the physical and pharmacological reasons for this conclusion are presented.

5. It is suggested that halothane by itself in oxygen is fully capable of providing all the necessities of safe and effective anaesthesia.

\section{ACK̉NOWLEDGMENTS}

We are indebted to Cyprane Limited of Keighley, Yorkshire, England, for providing a Fluotec vaporizer calibrated to give up to 10 per cent Halothane, and also for the Azeotec vaporizer used in the investigations. We are also most grateful to Dr. Victor J. Keating, Consultaint Anaésthetist, the General Infir:

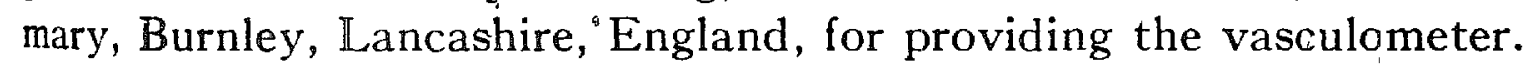

\section{RÉSUMÉ}

On est d'accord actuellement que, dans l'air, le mélange azéotrope halothaneéther n'est pas inflammable. Dans les mélanges de protoxide èt d'oxygène, la limite inférieure d'inflammabilité est $5.2 \% \mathrm{v} / \mathrm{v}$, concentration qui est de beaucoup inférieure à ce qui sort dés endroits d'évaporation de la plupart des 
vaporisateurs d'usage courant qui réalisent l'application du principe de saturer une partie du' débit gazeux et ensuite de diluer ce gaz saturé avec du gaz qui arrive "dans le circuit en évitant le vaporisateur. Si l'on emploie le mélange azéotrope pour renforcer l'anesthésie protoxide-oxygène, il faudra, en consć. quence, présumer que les risques d'explosion par l'électricité statique et les autres sources ne sont pas éliminés.

Au cours des douze derniers mois, nous avons fait des recherches qui nous permettent d'affirmer qu'il faut 6 à $10 \%$ d'halothane avec de l'oxygène pour induire une anesthésie en toute sécurité et dans un délai raisonnable chez des malades non atropinés. C'est une technique qui nous a donné d'excellents résultats chez plusieurs centaines de malades et nous a fourni une anesthésie assez profonde pour nous permettre d'intuber au bout de deux à quatre minutes tous les types de malades. Au retour à la /conscience, la plupart des malades ne se souviennent d'aucune odeau désagréable ni d'autre expérience subjective à part la perte soudaine de conscience. A la suite de l'induction de l'anesthésie avec cette concentration d'halothane dans l'oxygène, il èst possible de maintenir une anesthésie chirurgicale profonde durant de longues intervalles avec de 4 à $7 \%$ d'halothane dilué dans seulement 250 . à $500 \mathrm{ml}$. d'oxygène à la minute introduits dans un circuit fermé et avec respiration contrôlée. Des détails complets des aspects académiques et pratiques de cette méthode d'anesthésie sont en préparation pour publication. Nous avons da abandonner nos tentatives de faire la même chose àvec le mélange azéotrope parce que les malades se sont objectés violemment à l'odeur repoussante de la portion d'éther.

On a pensé que l'éther devrait contrebalancer les effets cardiovasculaires de l'halothane. On n'a pas songé à la possibilité que l'halothane puisse potentialiser l'action cardiotoxique de l'éther. Cette dernière possibilité est toutefois d'extrême importance parce qu'il est connu que la survie à la suite de l'éther n'a lieu que si le système sympathique est intact et, par ailleurs, nous savons que la réponse cardiovasculaire à l'halothane, pour une partie du moins, est attribuable à la dépression de l'activité sympathique.

Pour en venir à préciser si l'halothane augmente les dangers de l'éther, les auteurs ont administré le mélange azéotrope $3 \%$ avec de l'oxygène à une série de vingt vieillards déjà anesthésiés adéquatement avec l'halothane oxygène. Nous avons employé une méthode de recherche nọn utilisée antérieurement en anesthésie clinique, elle consiste en vasculométrie, vasculographie et sphygmomanométrie dont nous publierons les détails ailleurs. Nous avons observé que le mélange azéotrope a souvent causé un collapsus circulatoire profond en quelques minutes après son addition. L'élimination de l'éther et l'installation de nouveau de l'halothane à $2 \%$ avec de l'oxygène ont été suivies, dans tous les cas, de la disparition du collapsus circulatoire et nous avons conclu, en conséquence, que Whalothane sensibilisait "dangereusement les malades aux effets cardiotoxiques de l'éther.

\section{REFERENCES}

1. Hudon, F., Jaçęes, A., \& Boivin, P. A. Fluothane-Ether: An Azeotropic Mixture. Canad. Anaesth. Soc. J. 5: 403 (1958). 
2. Lotr, W. A. Medicinal Chemistry as a Basic Science in Anesthesiology. Anesth. \& Analg. 88: 461 (1959).

3. Borvin, P. A., Hudon, F., \& Jacques, A. Properties of the Fluothane-Ether Anaesthetic. Canad. Anaesth. Soc. J. 5: 409 (1958).

4: Raventos, J., \& DeE, J. The Action of the Halothane-Diethyl Ether Azcotropic Mixture on Experimental Animals. Brit. J. Anatsth. 31: 46 (1959).

5. Adams, A. K., Lambrechts, W., \& Pakknotski, J. Clinical Trial of an Azeotropic Mixture. Acta. Anaes. Scand. 3: 189 (1959).

6. Woons, M. A., \& BRown, T. A. A Marrett I)raw-Over Inhaler Modified for Halothane. Brit. J. Anaesth. 31:321 (1959).

7. Dobkin, A. B., Drummond, K., \& Purkix, N. Anaesthesia with the Azeotropic Mixture of Halothane and Diethyl Ether. Brit. J. Anaesth. 81. 321 (1959).

8. Dobkin, A. B., Harland, J. H., \& Fedoruk, S. Comparison of the Cardiovascular Effects of Halothane and the Halothane-Diethyl Fiher Azeotrope in Dogs. Anesthesiology 21: 13 (1960)

9 Paton, W. D. M. Halothane and Autonomic Nervous Activity. Lancet $i i$ : 554 (1959).

10. Dechene, J. P., \& Hebert, C. Fluothane-ether Anaesthesia for Pulmonary Surgery. Canad. Anaesth. Soc. J ${ }^{p}$ 7: $100(1960)$.

11. Wyant, G. W ; Merriman, J. E.; Harlanid, J. H:; \& Donaldonon, H. V. The Cardiovascular Effects of the Azeotropic Halothane-Ether. Cañad. Anaesth. Soc. J. \%: 91 (1960).

12. Keating, V. J. A Simple Pulse Indicator. Brit. Med. J. i: 1188 (1952).

13. Lax, H., Feinberg, A W., \& Cohen, B. M. Studies of the Peripheral Pulse Wave. J. Chron. Dis. 8: 618 (1956).

14. Schotz, S.; Bloom, S. S.; Helmsworth, F. W.; Eodge, H. C.; \& Birkmirl, E. L. The Ear Oximeter as a Circulatory Monitor. The I.R. Pulse: A Moment to Moment Guide to Cardiac Output. Brit. J. Anaesth. 81: 190 (1959).

15. Wright, S. Appliẹd Physiology. London: Oxford University Press (1940).

16. Wiggers, C. J. The Pressure Pulses in the Cardiovascular System. London and New York: Longmans, Green and Co. (1928).

17 Wiggers, C. J. Reminiscences and Adventures in Circulation Research. New York and London: Grune and Stratton (1958).

18. Johnstone, M. Collapse after Halothane. Anaesthesia 14: 410 (1959).

19 Johnstone, M. The Human Cardiovascular Response to Fluothane. Brit. J.e Anaestly. 28: 392 (1956).

20 Raventos, J. The Action of Fluothane - a New Volatile 'Anaesthetic. Brit. J. Pharmacol. 11: 394 (1956).

21 Price, H. L.; Linde, H. W.; Jones, R. E.; Bl.ACk, G. W.; \& Price, M. I. SympathoAdrenal Responses to General Anaesthesia in Man and their Relation to Haemodynamics. Anesthesiology 20: 563 (1959).

22 Thrower, W. B.; Darby, T. D.; Aldinger, E. E.; \& Sproux, J.H. Effects of Halothane Anaesthesia on the Ventricular Contractile "Force in the Human and" in the Dog. Fed. Proc. 19: 274 (1960).

23. Brewstek, W. R., IsaAcs, J. P, \& Andekson, T. W. The Effects of Ether on the Myocardium of the Dog and its Modification by the Reflex Release of Epinephrine and NorEpinephrine. Am J Physiol. 175: 399 (195:3). 